This item was submitted to Loughborough's Research Repository by the author.

Items in Figshare are protected by copyright, with all rights reserved, unless otherwise indicated.

\title{
The effects of gas diffusion layers structure on water transportation using $X$ - ray computed tomography based Lattice Boltzmann method
}

\section{PLEASE CITE THE PUBLISHED VERSION}

https://doi.org/10.1016/j.jpowsour.2017.12.016

\section{PUBLISHER}

(C) Elsevier

VERSION

AM (Accepted Manuscript)

\section{PUBLISHER STATEMENT}

This work is made available according to the conditions of the Creative Commons Attribution-NonCommercialNoDerivatives 4.0 International (CC BY-NC-ND 4.0) licence. Full details of this licence are available at: https://creativecommons.org/licenses/by-nc-nd/4.0/

\section{LICENCE}

CC BY-NC-ND 4.0

\section{REPOSITORY RECORD}

Jinuntuya, Fontip, Michael Whiteley, Rui Chen, and Ashley Fly. 2017. "The Effects of Gas Diffusion Layers Structure on Water Transportation Using X-ray Computed Tomography Based Lattice Boltzmann Method”. Loughborough University. https://hdl.handle.net/2134/28011. 


\title{
The effects of gas diffusion layers structure on water transportation using X-ray computed tomography based Lattice Boltzmann method
}

\author{
Fontip Jinuntuya ${ }^{a}$, Michael Whiteley ${ }^{b}$, Rui Chen $^{b^{*}}$, Ashley Fly $^{b}$ \\ ${ }^{a}$ Department of Mechanical Engineering, University of Phayao, Thailand \\ ${ }^{\mathrm{b}}$ Aeronautical \& Automotive Engineering, Loughborough University, United Kingdom
}

Highlights:

- X-ray computed tomography used to reconstruct three different types of GDL

- Models of GDLs analysed using Lattice Boltzmann method

- Invasion pattern and saturation of water in the GDLs is controlled by wettability

- Liquid water travelled with a stable displacement under hydrophilic angles

- Conversely, at hydrophobic contact angles it travelled with capillary fingering

\section{Abstract}

The Gas Diffusion Layer (GDL) of a Polymer Electrolyte Membrane Fuel Cell (PEMFC) plays a crucial role in overall cell performance. It is responsible for the dissemination of reactant gasses from the gas supply channels to the reactant sites at the Catalyst Layer (CL), and the adequate removal of product water from reactant sites back to the gas channels.

Existing research into water transport in GDLs has been simplified to $2 \mathrm{D}$ estimations of GDL structures or use virtual stochastic models. This work uses X-ray computed tomography (XCT) to reconstruct three types of GDL in a model. These models are then analysed via Lattice Boltzmann methods to understand the water transport behaviours under differing contact angles and pressure differences. 
In this study, the three GDL samples were tested over the contact angles of $60^{\circ}, 80^{\circ}, 90^{\circ}, 100^{\circ}, 120^{\circ}$ and $140^{\circ}$ under applied pressure differences of $5 \mathrm{kPa}, 10 \mathrm{kPa}$ and $15 \mathrm{kPa}$. By varying the contact angle and pressure difference, it was found that the transition between stable displacement and capillary fingering is not a gradual process. Hydrophilic contact angles in the region of $60^{\circ}<\theta<90^{\circ}$ showed stable displacement properties, whereas contact angles in the region of $100^{\circ}<\theta<140^{\circ}$ displayed capillary fingering characteristics. 


\section{Introduction}

With the recent proliferation of environmentally friendly consciousness regarding energy use, various sustainable energy conversion technologies have been explored to mitigate anthropogenic climate change concerns. One such technology is the hydrogen fuel cell. When sustainably sourced $\mathrm{H}_{2}$ is used as an input fuel, Polymer Electrolyte Membrane Fuel Cells (PEMFC) are considered to be zero-emissions energy conversion devices. Already used in commercial applications such as consumer electronics and automotive traction power units, the PEMFC has shown great promise. However, there are still areas that require improvement as to advance this promising technology; one of which is the performance of the cell.

The Gas Diffusion Layer (GDL) of a PEMFC plays a crucial role in overall performance in the form of providing unrestricted pathways for the reactant gases to be adequately transported from a gas channel in the separating plates to the Catalyst Layer $(\mathrm{CL})$, allowing the initiation of the reaction. The $\mathrm{GDL}$ is also responsible for the removal of product water from the $\mathrm{CL}$ to the gas channels, and ultimately out of the cell. The excessive presence of liquid water in the GDL drastically diminishes the performance of the cell by blocking reactant gas access to active sites in the CL. To this end, GDLs are normally treated with a hydrophobic coating (Polytetrafluoroethylene (PTFE)) to ease the removal of product water from the cell.

A wide range of studies have investigated water transport within a PEMFC in recent years, however the behaviour of liquid water in the GDL at a pore-level is currently inadequately understood. Experimental methods including Nuclear Magnetic Resonance (NMR) imaging, neutron imaging, $\mathrm{X}$ ray imaging, and direct optical visualisation remain difficult to fully understand at a microscopic level due to the limitations of spatial and temporal resolutions involved in such techniques [1].

Fluorescence microscopy techniques combined with conventional optical photography were used by Lister, et al. [2] to visualize through-plane liquid water transport in the GDL. Bazylak, et al. [3] from 
the same research group examined the influence of cell compression on the behaviour of liquid water transport in GDL materials using the same technique, finding that certain compressed regions of the GDL provided preferential pathways for liquid water transport, leading to a breakthrough in the test apparatus. Both works showed good advancements in visualisation of liquid water behaviour in a PEMFC GDL, however their technique was limited to the visualization of liquid water transport in the upper layers of the GDL due to the opacity of the material.

Prediction of the saturation distribution of liquid water has been modelled on a macroscopic level by numerous previous studies [4-10]. These models are based on volume averaging theory and make the assumption of homogeneous GDL material. Due to this, they fail to incorporate the influence of pore morphology of the GDL material on the transportation of liquid water [11]. Furthermore, these existing models depend upon empirical relationships of capillary pressure-saturation and relative permeability-saturation in order to predict liquid water behaviour within the GDL. Capillary pressure is normally expressed as a function of saturation using the Leverett function, and therefore is more likely to harbour inaccuracies as it was based upon experimental data of homogenous soil or sand with uniform wettability. These media differ significantly when compared to a GDL structure in a PEMFC [11-13].

To model on a pore-scale rather than macro-scale, techniques such as Pore Network (PN) and Lattice Boltzmann (LB) modelling have emerged as favourable methods for simulating fluid flow through porous media. In opposition to macro-scale techniques, PN and LB methods can uncover the underlying influence of microscopic features on liquid water transportation in the GDL structure.

Numerous PN models have been used to analyse water transportation in porous media, using 2D [14-18] and 3D [19-23] domains. In such works, however, the complex structure of the GDL material is often simplified to a regular sphere [23] or cubic pores [22] that are then connected via columnar throats for 3D PNs. 2D PNs are connected via an array of randomly distributed, equal-sized disks with random diameters [14,15]. 
The Lattice Boltzmann method has increased in popularity in recent years, due to its capability to incorporate complex boundaries of an actual $\operatorname{GDL}$ material as manufactured $[24,11]$. To date however, the majority of existing studies on fluid transport in GDL materials integrate artificial structures that are generated by stochastic simulation techniques [25-27]. The stochastic method uses a set of structural inputs obtained from design specifications or measured data to then reconstruct a porous medium [27]. However, this method is inadequate to fully reconstruct a GDL material sample. Another potential drawback to the use of stochastic methods is that it struggles to model the binding material that holds a GDL material together sufficiently. Many works therefore ignore the binder material altogether, resulting in an over-simplification and possibly altering the pore size and shape within the model.

For these reasons, XCT techniques have been increasingly used in this field to more accurately reconstruct the GDL material in a digital domain [28-31]. Rama et al. [24] undertook a study on the feasibility of using the combined methods of XCT and LB modelling to simulate liquid flow, at a pore scale, through PEMFC GDL materials. Their simulated results were compared to experimental results using a Frazier air tester, and their correlation error was found to be $3 \%$ greater than the measured one. This breakthrough, alongside numerous other studies [28-30], showed that XCT and LB are well suited for combination to accurately model liquid water flow through a PEMFC GDL.

Existing work by various authors shows that PEMFC GDLs have been heavily simulated using a variety of techniques to discover a wide range of results. The emerging methodology has been shown to be the use of XCT in combination with the LB method to simulate GDL water transport properties. Although existing work has looked into water flow through GDLs under differing operating conditions, there is little work in the area of differing wettability of XCT reconstructed GDLs, and this effect on water transport. 
To this end, this work looks at the water transport behaviour under varying wettability conditions by using XCT reconstructed GDL models of three types of commercial GDL material. These models are then analysed using the LB method.

The GDL wettability parameters are then altered so that the effect of this change can be analysed. The wettability of a GDL sample is defined by the contact angle $(\theta)$ of liquid water with the solid surface structure of the GDL sample. Hydrophilic wettability is considered to exist between $0^{\circ}<\theta<90^{\circ}$, and hydrophobic wettability is considered to exist between contact angles of $90^{\circ}<\theta<180^{\circ}$. The GDL samples were simulated between the full range of contact angles and at pressure difference of $5 \mathrm{kPa}$, $10 \mathrm{kPa}$, and finally $15 \mathrm{kPa}$.

\section{X-Ray Reconstructed GDL Models}

Three types of commercially available GDL materials were used in this study; Freudenberg H2315 felt, Toray TGP-H-120 paper and SGL 24AA paper. The GDL samples were untreated and contained no PTFE or Micro-Porous Layer (MPL) additions. All samples are similar in that they are all non-woven and are composed of multiple layers. Their inherent structure however, differs between samples. The Freudenberg felt has curved fibres travelling in both the in-plane and through-plane directions. Both the Toray and SGL papers have straight fibres which are mainly orientated in the in-plane direction. Both paper GDL fibres are held together by a carbonized binder, which differ in construction. The SGL binder has a rougher texture binder than the Toray paper, and it lies within the in-plane and through-plane directions, whereas the Toray binder is only located between layers in the in-plane direction.

Each sample was analysed through XCT processes at a resolution of $2.5 \mu \mathrm{m} / \mathrm{pixel}$, and reconstructed in digital form. A General Electric Phoenix nanotom ${ }^{\circledast}$ system was used, equipped with an X-ray source of $160 \mathrm{kV}(\max )$ and $250 \mu \mathrm{A}(\max )$, with an X-ray spot size of around $1 \mu \mathrm{m}$. 
The detector was a 5-megapixel flat panel CMOS (complementary metal-oxide semiconductor) with a GOS (gadolinium oxysulfide) scintillator deposited on a fibre optic plate.

The results of the scans are presented in Figure 1 alongside their 3D digital reconstructions. 


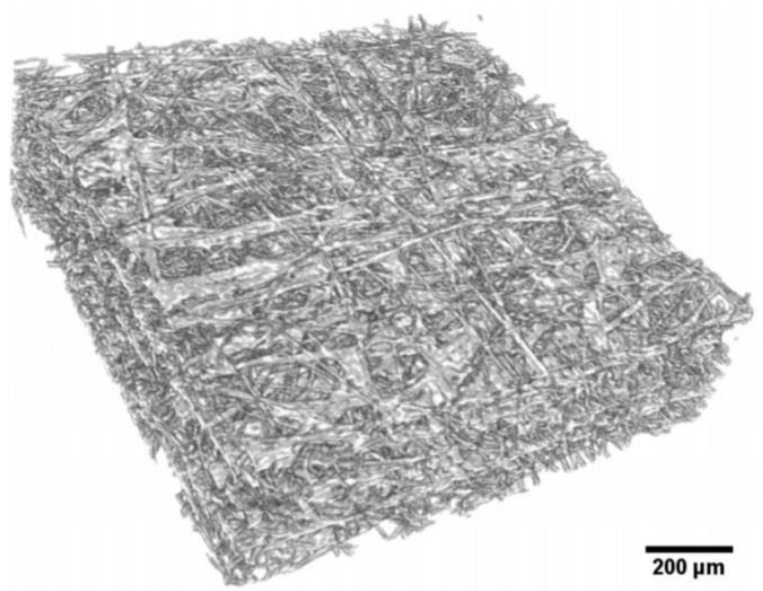

(a)

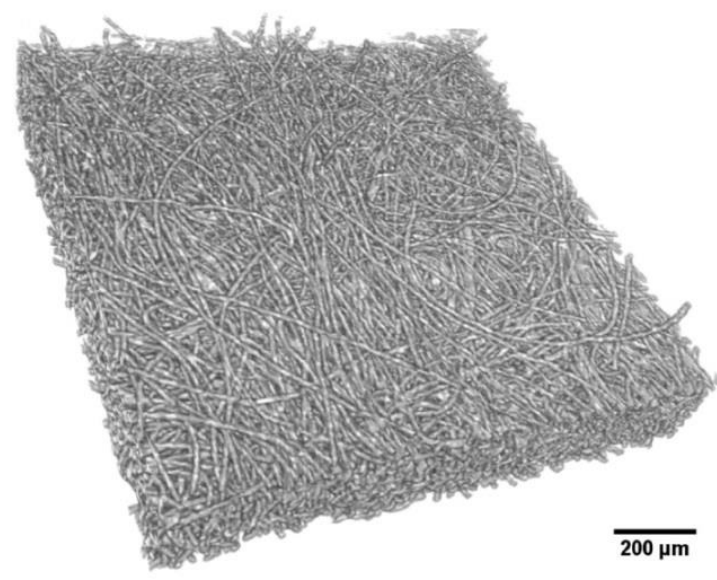

(b)

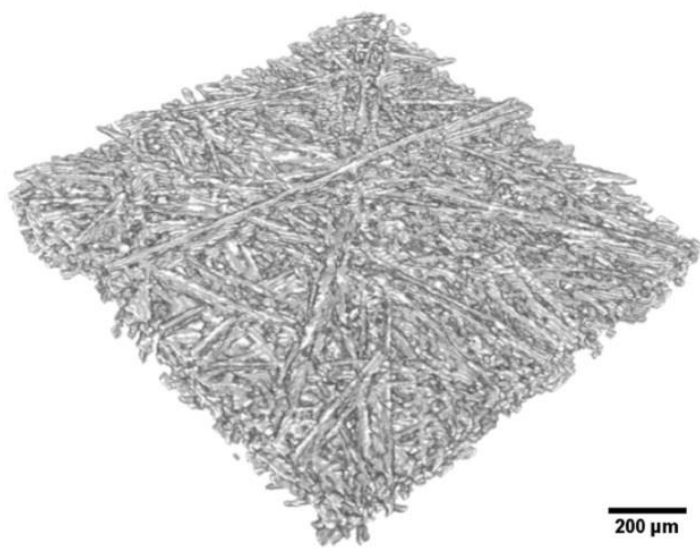

(c)

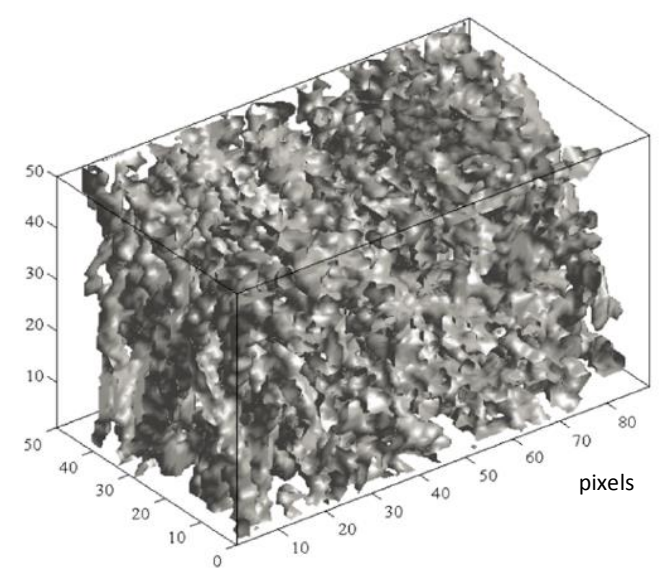

(d)

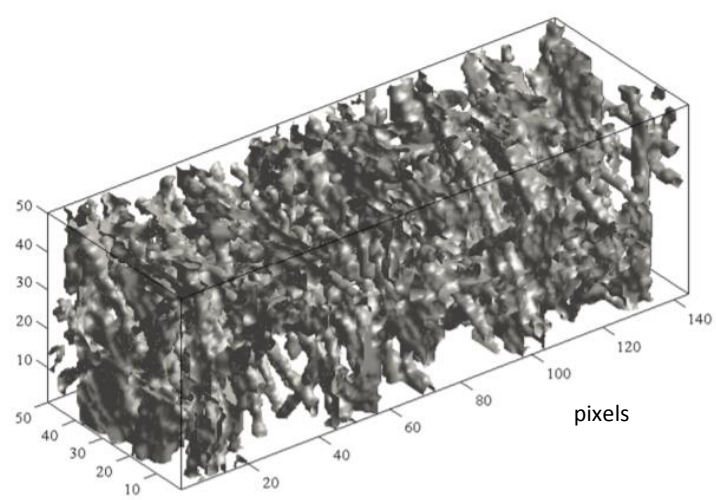

(e)

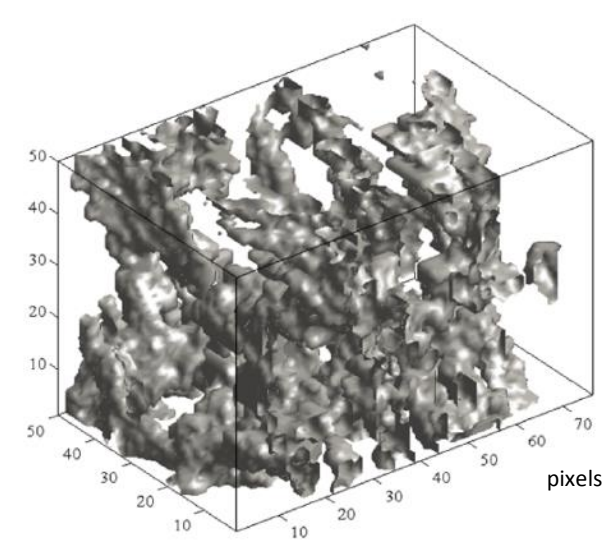

(f)

Figure 1-3D binary model of the Freudenberg felt, Toray paper, and SGL paper GDL samples, with their respective 3D digital 


\section{Two-Phase Lattice Boltzmann Modelling}

As discussed in Section 1, the LB method is widely used to model fluid particle flow through porous media. In this work, multiple relaxation time (MRT) LB methods were used, based upon the evolution of fluid particle distribution functions for each fluid, described in Equation 1.

$f_{i, k}\left(x+\xi_{i} \delta t\right)=f_{i, k}(x, t)+\Omega^{k}\left[f_{i, k}^{e q}(x, t)-f_{i, k}(x, t)\right]$

where $f_{i, k}(x, t)$ is the particle distribution function for fluid $k$ at location $x$ at time $t$, moving with velocity $\xi_{i}$ in the $i$ th direction, $f_{i, k}^{e q}(x, t)$ is the equilibrium distribution function for fluid $k$, which is the value of $f_{i, k}(x, t)$ at equilibrium state, $\delta t$ is a time increment during which the particle travels from one location to another, and $\Omega^{k}$ is the collision matrix. In this study, a 3-dimensional model with 19 lattice velocities (D3Q19) was utilized. The equilibrium distribution functions for each fluid for the D3Q19 model are given by Equations 2 \& 3.

$f_{i, k}^{e q}=w_{i} \rho_{k}\left[1-\frac{3}{2} u_{k}^{e q} \cdot u_{k}^{e q}\right] i=0$

$f_{i, k}^{e q}=w_{i} \rho_{k}\left[1+3 \xi_{i} \cdot u_{k}^{e q}+\frac{9}{2}\left(\xi_{i} \cdot u_{k}^{e q}\right)^{2}-\frac{3}{2} u_{k}^{e q} \cdot u_{k}^{e q}\right] i=1,2,3, \ldots, 18$,

where $w_{i}$ is a weighting factor depending on the magnitude of the velocity $\xi_{i}\left(w_{i}=1 / 3\right.$ for $\left|\xi_{i}\right|=0$, $w_{i}=1 / 18$ for $\left|\xi_{i}\right|=\delta x / \delta t$ and $w_{i}=1 / 36$ for $\left.\left|\xi_{i}\right|=2 \sqrt{\delta x / \delta t}\right)$.

The speed of sound is given by $c_{s}=\frac{1}{\sqrt{3}} \delta x / \delta t$.

The equilibrium velocity $u_{k}^{e q}$ for fluid $k$ is given by [32,33]

$\rho_{k} u_{k}^{e q}=\rho_{k} u^{\prime}+\tau_{k} F_{k}$

Where $u^{\prime}$ is the bulk fluid velocity of the two fluids, and it is calculated using: 
$u^{\prime}=\frac{\sum_{k} \rho_{k} u_{k} / \tau_{k}}{\sum_{k} \rho_{k} / \tau_{k}}$

Where $\rho_{k}$ is the macroscopic density of fluid $k$, and is calculated from:

$\rho_{k}=\sum_{i=0}^{18} f_{i, k}$

And $u_{k}$ is the velocity of fluid $k$, taken from:

$\rho_{k} u_{k}=\sum_{i=0}^{18} \xi_{i} f_{i, k}(x, t)$

The total force $F_{k}$ acting on the fluid $\mathrm{k}$ includes the fluid-fluid interaction $F_{f-f}^{k}$ and fluid-solid interaction $F_{f-s}^{k}$ and is expressed using:

$F_{k}=F_{f-f}^{k}+F_{f-s}^{k}$

\subsection{Model Validation}

Model validation is required as to confirm the accuracy of the simulation in relation to real-world results. The density $\left(\rho_{a} / \rho_{w}\right)$ and viscosity $\left(\mu_{a} / \mu_{w}\right)$ ratios of water and air are 1:800 and 1:15 respectively, which is beyond the capabilities of the LB method used in this work. Such high densities used in the LB method used in this work could lead to numerical instabilities $[28,29]$.

In order to determine whether liquid water transport through the GDL can be simulated using this technique, some non-dimensional parameters were calculated. The Bond number is representative of the ratio of gravitational force to interfacial force and is represented by:

$B o=g\left(\rho_{w}-\rho_{a}\right) D^{2} / \sigma$

The capillary number defines the ratio between viscous force and interfacial force, given by:

$\mathrm{Ca}=\mu_{a} U_{w} / \sigma$

The Reynolds number denotes the ratio between inertial force to viscous force, as presented by: 
$R e=\mu_{w} U_{w} / \sigma$

The Weber number is the ratio of inertial force to interfacial force

$W e=\rho_{w} U_{w}^{2} D / \sigma$

From these equations, $D$ is the average pore diameter in the GDL, $g$ is acceleration due to gravity, $U_{w}, \rho_{w}$ and $\mu_{w}$ are velocity, density and viscosities of water. Whereas $\rho_{a}$ and $\mu_{a}$ are the densities and viscosities of air respectively. Water-to-air interfacial tension is represented by $\sigma$.

An average pore diameter of $10 \mu \mathrm{m}$ was taken from the work in [28,29], and subsequently used in this work. Values for the Bond, capillary, Reynolds, and Weber were also taken from [29].

For a GDL in operation in a PEMFC, the three dimensionless numbers have approximate values of; $1.6 \times 10^{-4}, 2.47 \times 10^{-8}-1.92 \times 10^{-7}, 1.65 \times 10^{-4}-2.12 \times 10^{-4}$, and $4.08 \times 10^{-12}-4.07 \times 10^{-11}$ for Bond, capillary, Reynolds and Weber numbers respectively. From these numbers it is clear that the effect of gravity is negligible with respect to the interfacial tension force. Also, the viscous force is negligible when compared to the capillary force. Likewise, the inertial force is negligible when compared to the viscous force.

To this end, the viscosity difference and large density of air and water, which in turn have an effect on inertial, gravitational and viscous forces, would seem to have very limited effect on liquid water transport in a PEMFC GDL. Thus, it is concluded from the above, that water intrusion into PEMFC GDLs is mainly controlled by capillary action.

For a two-phase LB model to accurately simulate water transport, two input variables are required. The fluid-fluid interaction strength parameter, given by $g_{k \bar{k}}$, and the fluid-solid strength parameter given by $g_{k s} \cdot g_{k \bar{k}}$ denotes the fluid-fluid interfacial tension, whereas $g_{k s}$ is responsible for denoting the wettability of the solid wall. These parameters are not practically measurable, and therefore a 
series of numerical experiments were undertaken [28] to ascertain values. Said values were used in this study.

\subsection{Simulation Boundary Setup}

To simulate water transport through an initially dry GDL, a water reservoir was added to the front end of the GDL structure, and an air reservoir at the end. A difference in pressure was then introduced between the two to force water across the material in the through-plane direction. The remaining four boundaries to the model were treated as periodic boundaries, meaning that any particle leaving the domain would then return to the other side of the domain with the same properties. As discussed in section 3, a three-dimensional model with 19 velocity directions (D3Q19) was used for this simulation. The Isothermal condition is assumed for this work.

The digital reconstruction of each GDL sample is shown in Figure 1d-f.

Both the digital and physical dimensions of each sample is shown in Table 1:

Table 1 - Digital and Physical dimensions of each sample GDL

\begin{tabular}{|l|l|l|l|}
\hline Sample & Freudenberg H2315 & Toray TGP-H-120 & SGL 24AA \\
\hline Resolution $(\mu \mathrm{m} /$ pixel) & 2.5 & 2.5 & 2.5 \\
\hline Digital size $\left(\mathrm{pixel}^{3}\right)$ & $50 \times 50 \times 89$ & $50 \times 50 \times 114$ & $50 \times 50 \times 76$ \\
\hline Physical size $\left(\mu \mathrm{m}^{3}\right)$ & $125 \times 125 \times 222.5$ & $125 \times 125 \times 360$ & $125 \times 125 \times 190$ \\
\hline
\end{tabular}

\subsection{Simulation Process}


All of the GDL samples analysed using XCT methods were tested with contact angles of $60^{\circ}, 80^{\circ}, 90^{\circ}$, $100^{\circ}, 120^{\circ}$ and $140^{\circ}$, using applied pressure differences of $5 \mathrm{kPa}, 10 \mathrm{kPa}$ and $15 \mathrm{kPa}$. In doing so, greater comparisons can be drawn from the effects that these variables have on water transport in each GDL sample.

The simulations were run until liquid water broke through to the air side, or until it was clear that water would not progress any further under those conditions.

\section{Results and Discussion}

\subsection{Invasion Pattern}

Figures 2-4 show the water intrusion pattern at varying stages during the simulation and at varying contact angles. The first image shows the initial stage of water intrusion, whereas the third image to the right shows the final stage, either at breakthrough or stagnation. The top row is the shallowest contact angle of $60^{\circ}$, and the bottle row is the steepest of $140^{\circ}$. This is shown for each pressure difference of $5 \mathrm{kPa}, 10 \mathrm{kPa}$, and $15 \mathrm{kPa}(\mathrm{a}, \mathrm{b}$, and c respectively). 

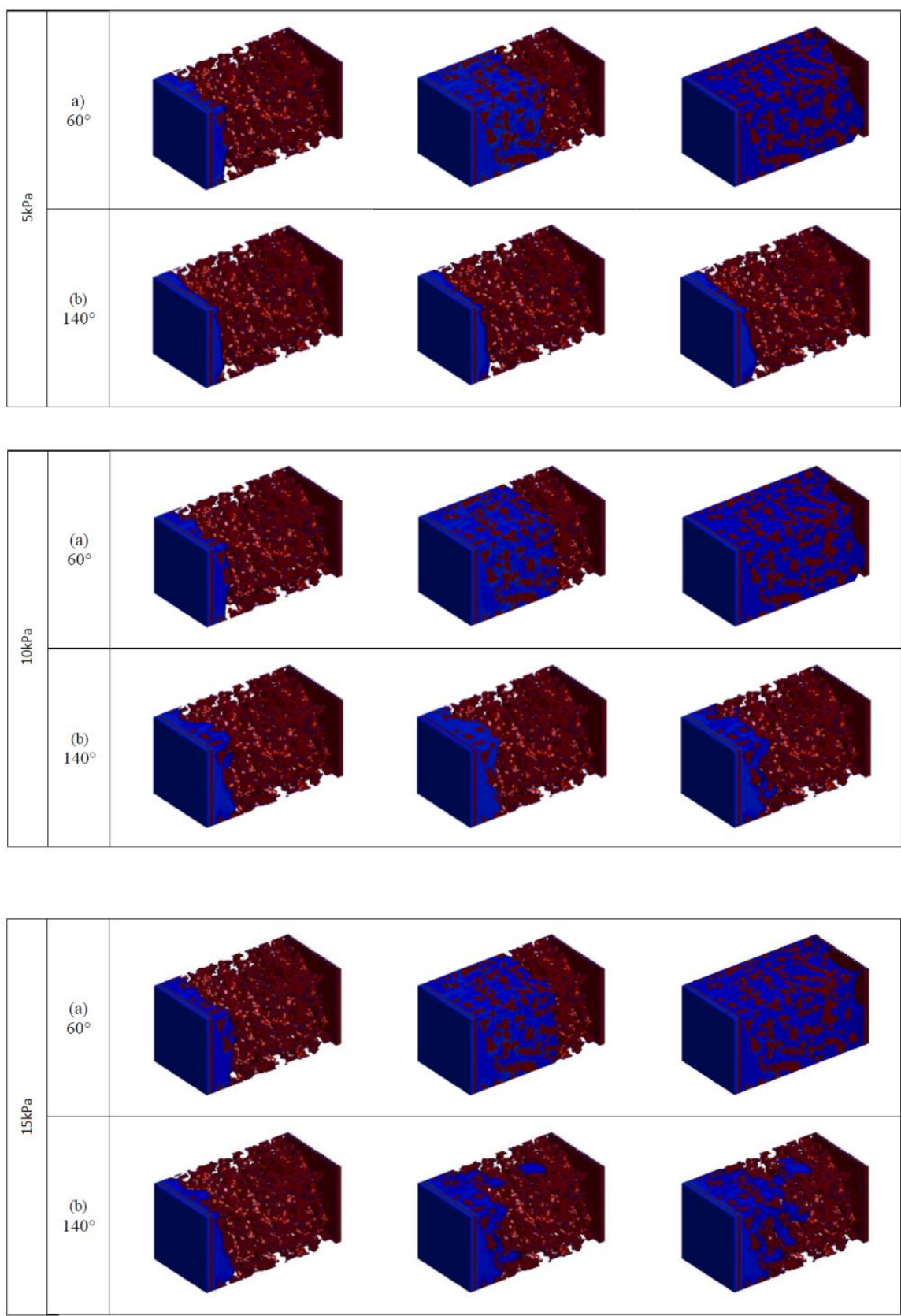

Figure 2 - Freudenberg felt intrusion patterns at contact angle of a) $60^{\circ}$ b) $140^{\circ}$ under $5 \mathrm{kPa}, 10 \mathrm{kPa}$, and $15 \mathrm{kPa}$ pressure differences 

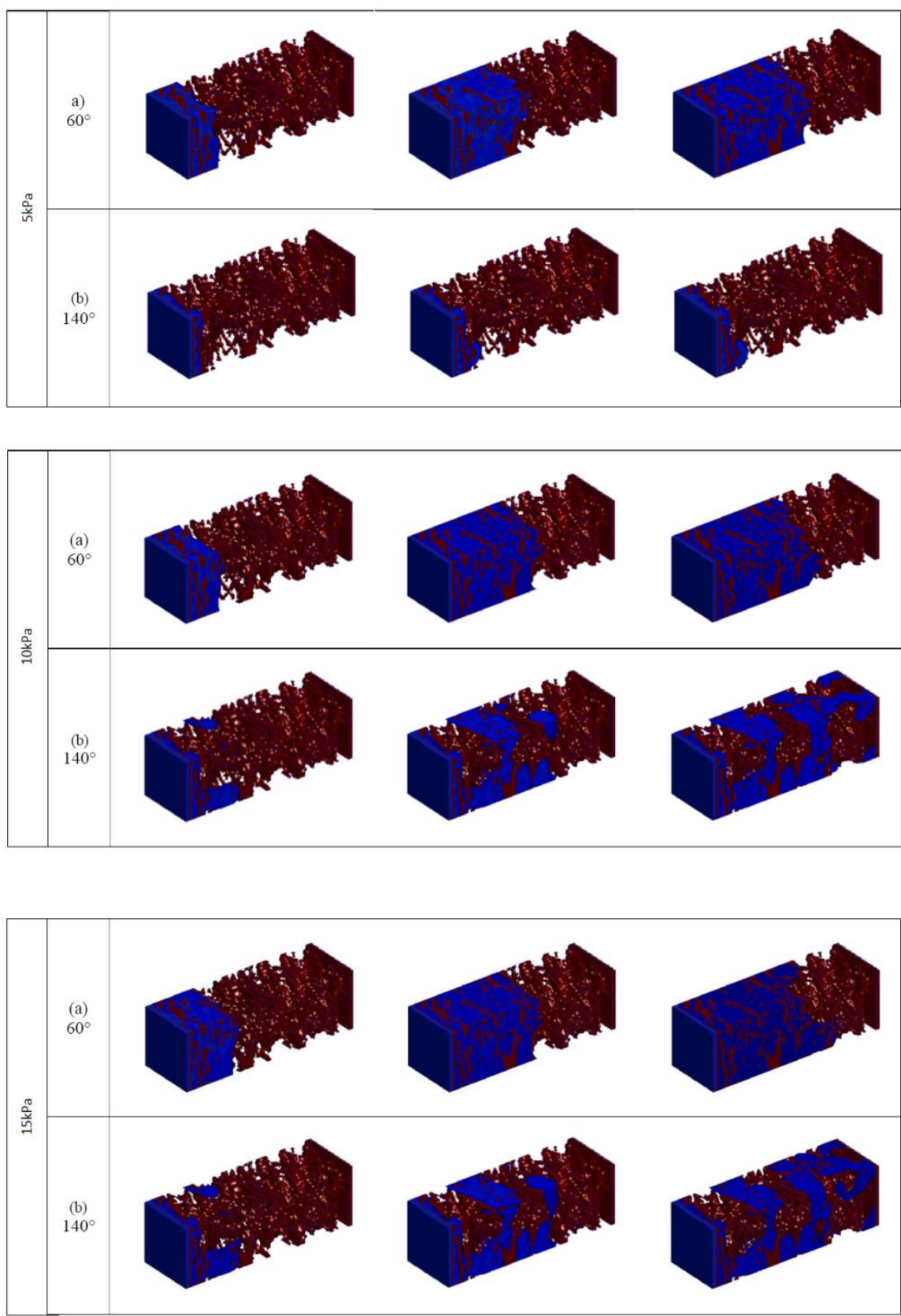

Figure 3 - Toray paper intrusion patterns at contact angle of a) $60^{\circ}$ b) $140^{\circ}$ under $5 \mathrm{kPa}, 10 \mathrm{kPa}$, and $15 \mathrm{kPa}$ pressure differences 

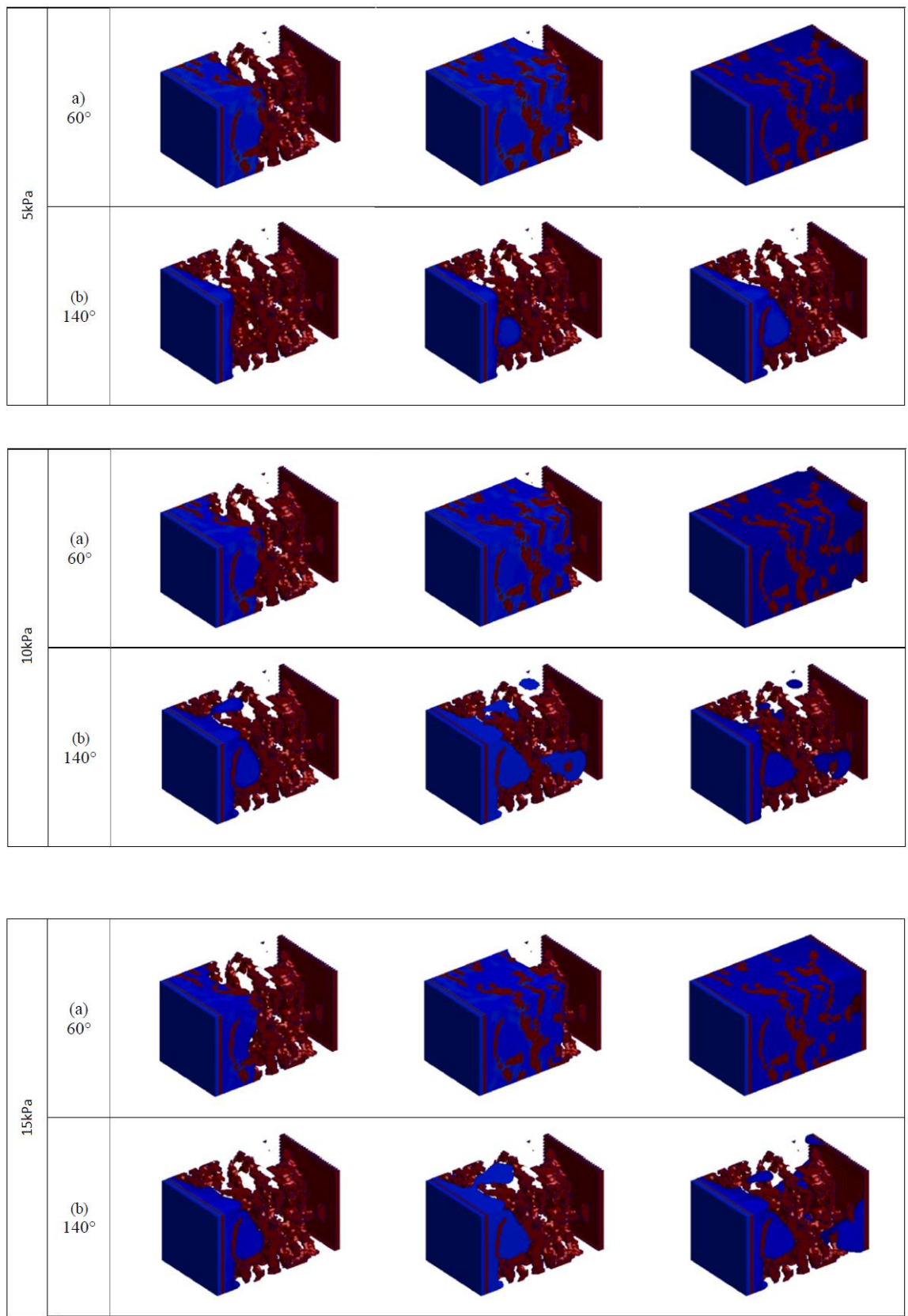

Figure 4 - SGL paper intrusion patterns at contact angle of a) $60^{\circ}$ b) $140^{\circ}$ under $5 \mathrm{kPa}, 10 \mathrm{kPa}$, and $15 \mathrm{kPa}$ pressure differences

\subsubsection{Effects of GDL Wettability}

As can be seen in Figures 2-4, the contact angles or wettability of each sample greatly determines the invasion pattern of liquid water through the samples. As the wettability changes from hydrophilic to hydrophobic, as determined by the contact angle change, the water invasion also 
changes. For contact angles representing a hydrophilic sample, water displaces air in a uniform manner, with homogenous invasion properties. As the water passed through the sample, it saturates all pores with a flat invasion front. For more moderate contact angles and hydrophilic tendencies, capillary resistance force depends little on the pore size. Because of this, it is easy for the water to fill the pores, both large and small, resulting in the observed homogenous invasion front. This phenomenon is termed 'stable displacement'. This stable displacement was observed for all sample GDLs, and these results agree with the work in [34].

When the contact angles change to hydrophobic, water transport is no longer of stable displacement, and instead it passes through the structure partially saturating the domain, occupying certain voids in the GDL's porous network. This phenomenon is termed 'capillary fingering'. This observation is shared with $[27,29,34]$.

The results in this study show that the transition between stable displacement and capillary fingering phenomena occurs abruptly, from $60^{\circ}<\theta<90^{\circ}$ to $100^{\circ}<\theta<140^{\circ}$. This does not agree with the work in [16] that shows the transition occurring at a contact angle of $90^{\circ}$. This study shows that the transition occurs in the region of $100^{\circ}<\theta<120^{\circ}$ in the case of the Freudenberg felt, and $90^{\circ}<\theta<100^{\circ}$ for the Toray paper. However, without further studies to evaluate smaller increments of contact angle, a precise angle cannot be confirmed.

\subsubsection{Effects of GDL Structure}

Although all sample GDLs showed capillary fingering at hydrophobic contact angles, the nature of this movement differs between samples. With the Freudenberg felt GDL, water entering the GDL forms convex water fronts because of the inherent hydrophobicity of the material. The liquid water penetrates the sample with a finger-like invasion pattern. The water selects some preferred pathways through the sample depending upon the local capillary resistance force. 
In contrast to the Freudenberg felt, the Toray paper sample shows water travelling through the inplane direction clearly. Liquid water enters from the front and travels selectively through large pores in the through-plane direction. However, at certain cross sections (at around $35 \%$ and $70 \%$ thickness) water then invades the in-plane direction and occupies all pores at that cross-section.

This difference highlights the difference in GDL construction between the two samples.

\subsubsection{Effects of Applied Pressure Difference}

Analysing the results of the differing pressures that the samples were subjected to shows that pressure difference has no effect on the intrusion pattern of liquid water. Although pressure difference has no effect on invasion pattern, the pressure does affect how far the water can penetrate through the sample.

All three samples showed the same stable displacement behaviours under hydrophilic contact angles for each pressure difference. At hydrophobic contact angles, capillary fingering behaviours were observed throughout the pressure range. The only exception being with the Freudenberg felt GLD at $5 \mathrm{kPa}$ pressure difference, which showed a stable displacement for all contact angles. This is attributed to the surface wettability and the resulting capillary resistance force where the contact angles $\left(120^{\circ}\right.$ and $\left.140^{\circ}\right)$ create high capillary resistance, meaning that a higher pressure is needed for transformation. Our observations show that water travels only a very short distance before stopping at about $10 \%$ thickness. It is assumed that an increase in pressure difference above $5 \mathrm{kPa}$ allows capillary fingering to occur.

\subsection{Water Saturation Distribution}

Figures 5-7 show liquid water evolution through the three GDL structures at different times throughout the simulation. The water saturation distribution graph for the contact angle of $60^{\circ}$ is 
first shown, with the most sever contact angle presented to the right $\left(140^{\circ}\right)$ for each pressure difference $(5 \mathrm{kPa}, 10 \mathrm{kPa}, 15 \mathrm{kPa})$.

These figures offer the average cross-sectional saturation levels along the through-plane direction of each sample. This average is defined as the ratio of area occupied by liquid water to the overall void area in the given cross-section. Given this, the saturation level lies in the range of zero to one. Zero denoting the absence of water, and one showing a fully saturated region.

These figures confirm the observations from Figures 2-4 in that the evolution of water distribution follows a stable displacement pattern to capillary fingering pattern from hydrophilic to hydrophobic contact angles.

Stable displacement patterns can be observed via the somewhat flat saturation front profile, confirming water occupying almost all of the voids in the GDL cross-section. Contrary to this, capillary fingering can be seen by the complex saturation profile with concaved shapes, confirming that water is only partially filling certain voids.

\subsubsection{GDL With Felt Structure}

The Freudenberg felt sample showed stable displacement at all contact angles at $5 \mathrm{kPa}$ pressure difference. At the same pressure difference, the intrusion distance of water decreased with an increasing contact angle. Water passed through the sample thickness in all contact angles from hydrophilic to moderate $\left(90^{\circ}\right)$. However, when these angles are increased a longer period of time is needed for breakthrough (from $98.96 \mathrm{~ms}$ at $60^{\circ}$ to $203.13 \mathrm{~ms}$ at $90^{\circ}$ ). Water fails to pass through the GDL at $100^{\circ}$ angle and above.

At $10 \mathrm{kPa}$ differences in pressure, stable displacement is shown and breakthrough is shown up until $100^{\circ}$ contact angle. At angles of $120^{\circ}$, water passed through the sample thickness with capillary fingering behaviour, with a substantial drop in saturation level. At $140^{\circ}$, water is still travelling with 
capillary fingering but saturation stops at around $40 \%$ thickness, as can be observed in Figure $\mathbf{5 b}$. This saturation level is around $20 \%$ greater than the $5 \mathrm{kPa}$ example (Figure 5a), showing how pressure difference influences water intrusion distance.

Increasing the pressure difference to $15 \mathrm{kPa}$ shows the same behaviour as the previous pressure differences, however water breaks through in all cases.

Breakthrough time increased with contact angles, from $41.67 \mathrm{~ms}$ at $60^{\circ}$ to $109.38 \mathrm{~ms}$ at $140^{\circ}$. This time is also increased by increasing pressure difference from 5-15 $\mathrm{kPa}$. 
(a)

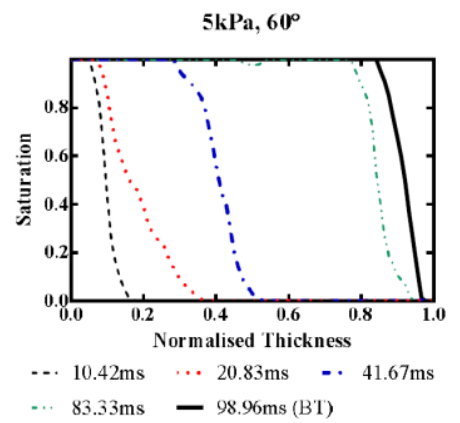

(b)

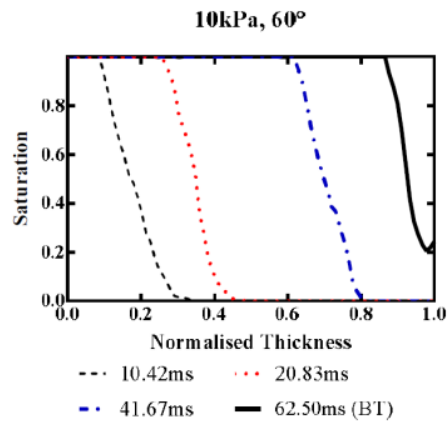

(c)

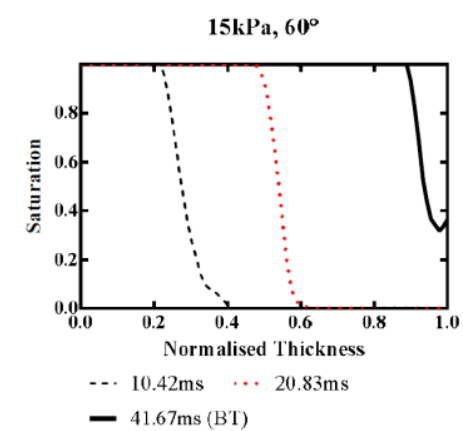

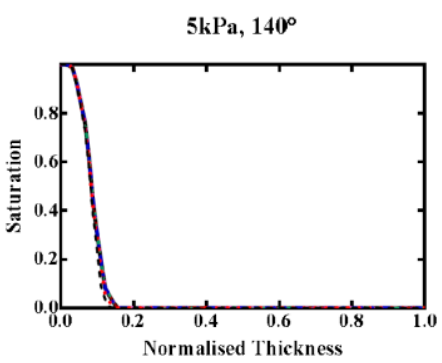

-.. $26.04 \mathrm{~ms} \quad$ ․ $52.08 \mathrm{~ms} \quad$-. $104.17 \mathrm{~ms}$ $\begin{array}{llllllllll}\cdots & 208.33 \mathrm{~ms} & \cdots & 312.50 \mathrm{~ms} & \cdots & 416.67 \mathrm{~ms}\end{array}$ $-520.84 \mathrm{~ms}$

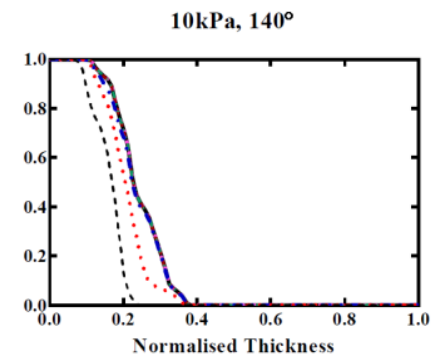

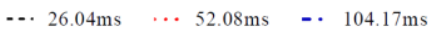

$\begin{array}{lllll}-\cdots & 208.33 \mathrm{~ms} & -- & 312.50 \mathrm{~ms} \quad \cdots & 416.67 \mathrm{~ms}\end{array}$

- $520.84 \mathrm{~ms}$

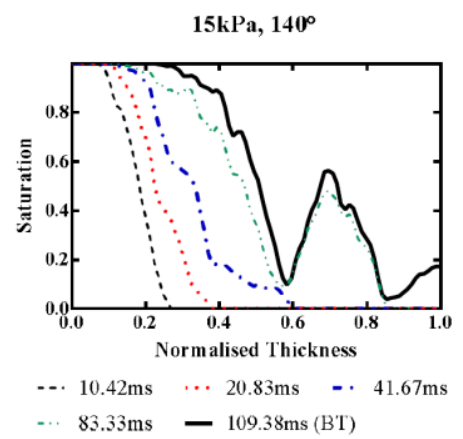

Figure 5 - Water distributions across the thickness of the Freudenberg felt at $60^{\circ}$ and $140^{\circ}$ contact angles at the applied pressure difference of (a) $5 \mathrm{kPa}$, (b) $10 \mathrm{kPa}$, and (c) $15 \mathrm{kPa}$.

\subsubsection{GLD with paper structure}

The Toray GDL paper showed stable displacement fronts at hydrophilic and moderate contact angles (until $100^{\circ}$ ), changing to capillary fingering at angles above $120^{\circ}$. With a pressure difference of $5 \mathrm{kPa}$ no contact angles showed water breakthrough. Up until $100^{\circ}$, water can penetrate the GDL to around $60-70 \%$ thickness, whereas at higher contact angles $\left(120^{\circ}+\right)$ water stops at around $15-20 \%$ thickness. 
Notably, at the contact angle of $100^{\circ}$ and $5 \mathrm{kPa}$, stable displacement is observed, however small pockets of air are not displaced by water at $208.33 \mathrm{~ms}$ and $416.67 \mathrm{~ms}$. These pockets of air are subsequently filled with water at later time-steps, showing early onset capillary fingering.

The same trends as above are shown in the 10 and $15 \mathrm{kPa}$ runs. Under a pressure difference of 10 $\mathrm{kPa}$ at an angle of $100^{\circ}$ water front profiles show a large decrease in saturation in cross sections at $31.25 \mathrm{~ms}$ and $62.50 \mathrm{~ms}$, with $20 \%$ of void spaces not occupied by water.

At $15 \mathrm{kPa}$ at the same angle, stable displacement is shown with a flat front profile but small pockets are not filled with water until around $125 \mathrm{~ms}$.

At angles of $120^{\circ}$ and $140^{\circ}$ under $10 \mathrm{kPa}$ and $15 \mathrm{kPa}$, the sample thickness is fully saturated further down the thickness of the GDL, as seen in Figure $\mathbf{6 b}$ and $\mathbf{6 c}$. This behaviour differs from the Freudenberg sample, where once water saturation has dropped, it never recovers. 
(a)

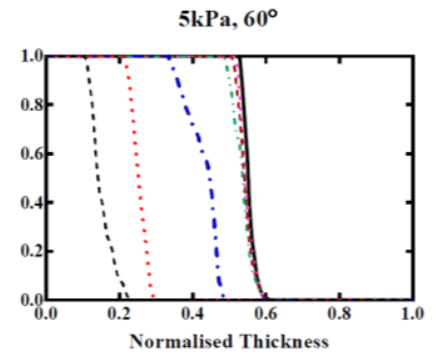

․ $26.04 \mathrm{~ms} \quad \cdots \quad 52.08 \mathrm{~ms} \quad$-. $104.17 \mathrm{~ms}$

$\begin{array}{ccccc}208.33 \mathrm{~ms} & \cdots & 312.50 \mathrm{~ms} \quad \cdots & 416.67 \mathrm{~ms}\end{array}$

- $520.84 \mathrm{~ms}$

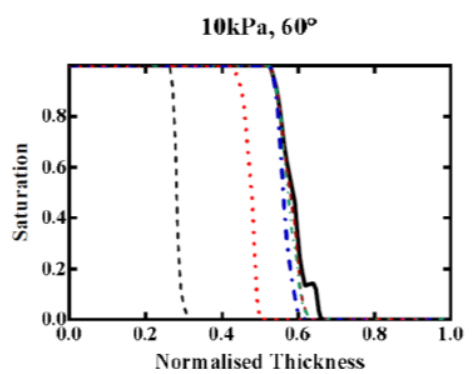

$\begin{array}{llll}\cdots & 31.25 \mathrm{~ms} \quad \cdots & 62.50 \mathrm{~ms} \quad \text {-. } 125.00 \mathrm{~ms}\end{array}$ $187.50 \mathrm{~ms} \quad \cdots 250.00 \mathrm{~ms}-312.50 \mathrm{~ms}$

(c)

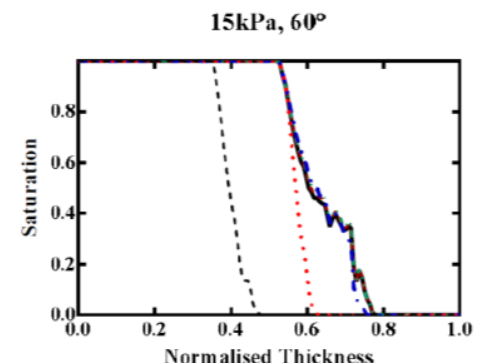

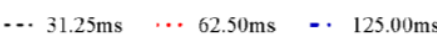

$\begin{array}{llll}\cdots & 187.50 \mathrm{~ms} & \cdots & 250.00 \mathrm{~ms} \quad-312.50 \mathrm{~ms}\end{array}$

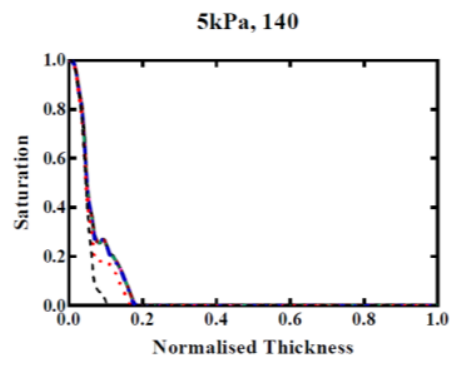

-.. $26.04 \mathrm{~ms} \quad$-.. $52.08 \mathrm{~ms} \quad$-. $104.17 \mathrm{~ms}$

$\begin{array}{lllll}208.33 \mathrm{~ms} & \cdots & 312.50 \mathrm{~ms} \quad \cdots & 416.67 \mathrm{~ms}\end{array}$

$-520.84 \mathrm{~ms}$

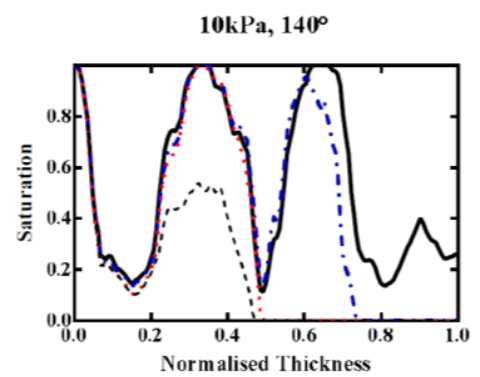

-.. $31.25 \mathrm{~ms} \quad \cdots 62.50 \mathrm{~ms}$

-. $125.00 \mathrm{~ms}-182.29 \mathrm{~ms}(\mathrm{BT})$

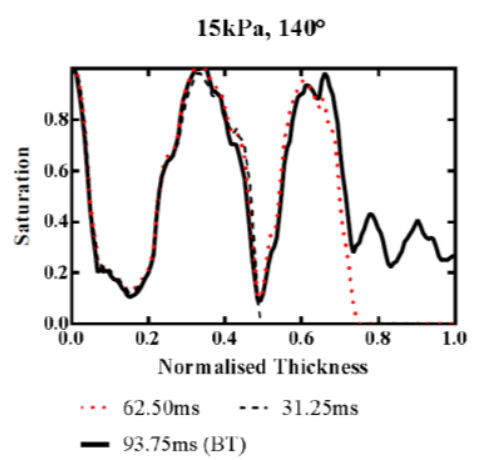

Figure 6 - Water distributions across the thickness of the Toray paper at $60^{\circ}$ and $140^{\circ}$ contact angles at the applied pressure difference of (a) $5 \mathrm{kPa}$, (b) $10 \mathrm{kPa}$, and (c) $15 \mathrm{kPa}$.

Additionally, unlike the Freudenberg GDL, the Toray paper at 10-15 kPa pressure differences shows breakthrough time decreases from $229.17 \mathrm{~ms}$ at $120^{\circ}$ and $182.29 \mathrm{~ms}$ at $140^{\circ}$ for $10 \mathrm{kPa}$, and 98.96 ms to $93.75 \mathrm{~ms}$ for the $15 \mathrm{kPa}$ pressure difference. Again, the increased pressure difference of $10-15$ $\mathrm{kPa}$ significantly decreases time to breakthrough, which is around $50 \%$ for both cases. 
The SGL paper GDL material shows similar characteristics to the felt GDL material. Stable displacement is displayed at $5 \mathrm{kPa}$ at hydrophilic angles, whereas capillary fingering is shown at hydrophobic angles. These patterns change at around $100^{\circ}$ contact angle, noted by a sudden drop in saturation at $156.25 \mathrm{~ms}$ in the $100^{\circ}$ case. Notably however, after the drop in saturation, saturation is regained as time moves on and the profile becomes flat and stable again.

Up until $120^{\circ}$ contact angle at $5 \mathrm{kPa}$ water passes through the sample consistently and breaks through, with the time to breakthrough increasing from $104.17 \mathrm{~ms}$ at $60^{\circ}$ to $291.67 \mathrm{~ms}$ at $120^{\circ}$. However at $140^{\circ}$ water does not break through the sample thickness, stopping at around $40 \%$ thickness. This suggests the contact angle's effects on breakthrough where higher contact angles create more capillary resistance and prohibit water passage.

$10 \mathrm{kPa}$ and $15 \mathrm{kPa}$ pressures show a similar behaviour with stable displacement throughout hydrophilic angles and capillary fingering for hydrophobic angles $\left(100^{\circ}+\right)$. Saturation figures also show increasing breakthrough time with increased pressure, from $62.50 \mathrm{~ms}$ at $60^{\circ}$ to $72.92 \mathrm{~ms}$ at $90^{\circ}$ for $10 \mathrm{kPa}$. For $15 \mathrm{kPa}$, the times increase from $41.67 \mathrm{~ms}$ at $60^{\circ}$ to $46.88 \mathrm{~ms}$ at $90^{\circ}$. However conversely, the breakthrough time decreases in the hydrophobic region, with $78.13 \mathrm{~ms}$ at $100^{\circ}$ to $52.08 \mathrm{~ms}$ at $140^{\circ}$ at $10 \mathrm{kPa}$ and $36.46 \mathrm{~ms}$ at $100^{\circ}$ to $26.04 \mathrm{~ms}$ at $140^{\circ}$. This is similar behaviour to the Toray paper GDL. 

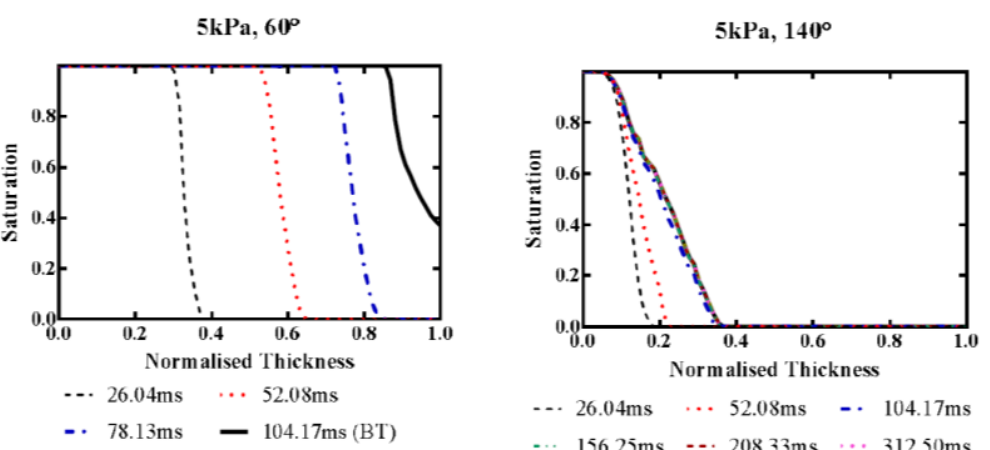

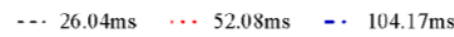

‥ $156.25 \mathrm{~ms} \quad \cdots \quad 208.33 \mathrm{~ms} \quad \cdots 312.50 \mathrm{~ms}$

-. $416.67 \mathrm{~ms}-520.84 \mathrm{~ms}$

(b)
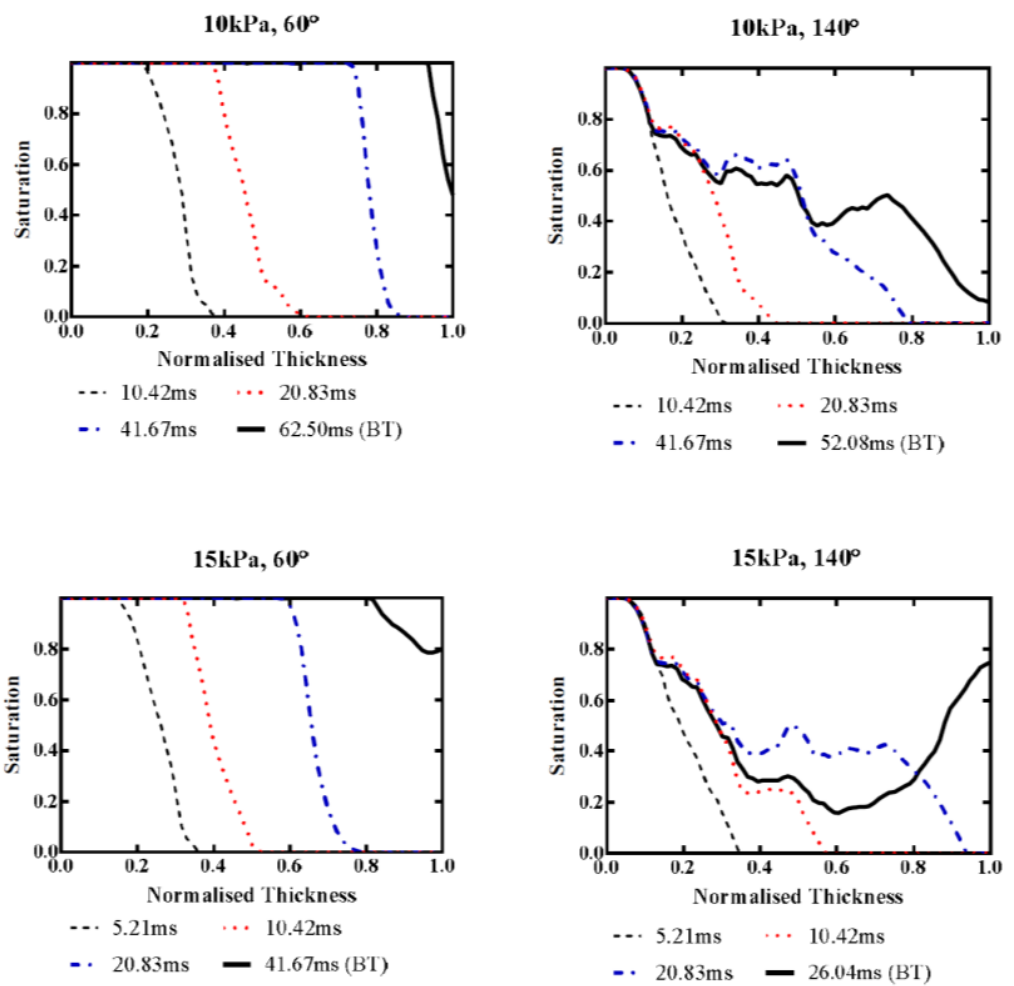

Figure 7 - Water distributions across the thickness of the SGL paper at $60^{\circ}$ and $140^{\circ}$ contact angles at the applied pressure difference of (a) $5 \mathrm{kPa}$, (b) $10 \mathrm{kPa}$, and (c) $15 \mathrm{kPa}$

\subsection{Breakthrough Behaviour}

Various similarities and differences can be drawn from the breakthrough characteristics of each GDL construction type. The Freudenberg felt experiences breakthrough at almost all contact angles, from hydrophilic, all the way through to hydrophobic. However, the Toray paper type GDL shows 
breakthrough characteristics only in hydrophobic contact angles. SGL GDLs, as per the Freudenberg felt, experiences breakthrough at all contact angles.

The inherent construction of each sample shines some light on why this is the case. The Freudenberg felt has a 3D structure where the fibres travel in the through-plane and in-plane directions. In this case, there is no requirement for a binder material. The vast majority of its fibres run in the in-plane direction, allowing for local saturation. At hydrophilic contact angles, the through-plane fibres accommodate the adhesion of water to these fibres, leading to saturation through the thickness of the GDL, allowing stable displacement.

In contrast to this, the Toray paper has a 2D structure, with fibres only travelling in the in-plane direction. Therefore, a binding agent is required for structural integrity. In addition to reducing pore size and porosity of the material, the carbonized binder increases the contact area between solid surface and liquid water. This increased surface area of the binder would hold more water than if a binder was not used. This explains the layered saturation characteristics of this sample.

The SGL paper also uses a binder; however, it is a rough binder and not a layered type. This binder is spread over the fibres through the in-plan and through-plane directions, forming a 3D staircase-like structure. This allows the sample to draw in water to move into the sample domain in the thickness direction and then breakthrough at hydrophobic angles. This discovery shows that the binder in paper GDLs plays a significant role in water transport behaviour.

\subsection{Breakthrough Saturation Levels}

The point where water breaks through the outlet of each sample is shown in Figure 8. These breakthrough saturation levels were noted at each contact angle from $60^{\circ}$ to $140^{\circ}$ and under each pressure difference of 5-15 kPa.

\subsubsection{Freudenberg Felt GDL}


Figure $8 \mathrm{a}$ shows that at all three pressure differences showed similar saturation levels at breakthrough. At lower and intermediate contact angles saturation levels were around $100 \%$, showing that water occupied all of most of the void spaces. Alternatively, these saturation levels decreased from full saturation at more hydrophilic contact angles, to partial saturation at intermediate to higher hydrophobic domains. Higher contact angles, in the region of $140^{\circ}$, these levels reduce to around $62.5 \%$.

This change in saturation levels from full to partial occurs in the region of $100^{\circ}$ and $120^{\circ}$, with full saturation observed at $100^{\circ}$ but an $18.7 \%$ reduction in saturation at $120^{\circ}$, confirming the influence of hydrophobicity on saturation in the felt GDL.

\subsubsection{Toray paper GDL}

As can be seen in Figure $8 \mathrm{~b}$, contact angles of $110^{\circ}, 115^{\circ}$, and $130^{\circ}$ showed a decreasing trend in saturation levels. It was found that breakthrough only occurs under pressure differences of $10 \mathrm{kPa}$ and $15 \mathrm{kPa}$, and at contact angles of $115^{\circ}$ and upwards. Saturation levels at breakthrough characteristics decrease as the contact angle increases.

For example, at $140^{\circ}$ with $15 \mathrm{kPa}$ pressure difference, the saturation level at breakthrough is $54.3 \%$.

\subsubsection{SGL paper GDL}

Similar in respect to the Freudenberg felt GDL in that GDL wettability significantly affects saturation levels at breakthrough. Lower and intermediate contact angles show saturation levels at $100 \%$, showing that water fills the entire GDL domain when water breaks through the material. With higher contact angles however, decreased saturation levels are observed. At angles of $140^{\circ}$ this drop is in the region of $39.2 \%$. Figure $8 \mathrm{c}$ shows full saturation at $90^{\circ}$, but at $100^{\circ}$ there is an $8.3 \%$ reduction in saturation, suggesting hydrophobicity's impact on saturation in SGL GDLs. 

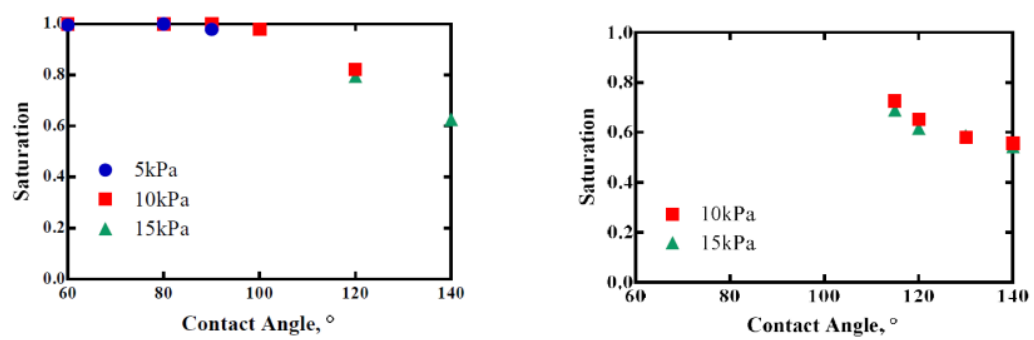

(a)

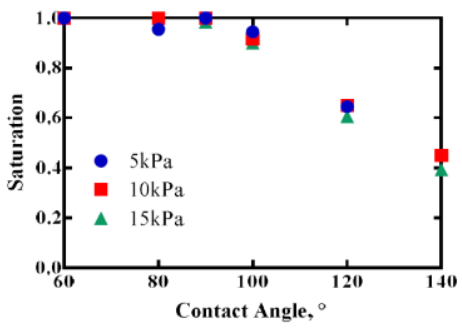

(c)

Figure 8 - Water saturation levels at breakthrough for (a) Freudenberg felt (b) Toray paper (c) SGL paper

For all three GDL samples, the results showed that a contact angle is the major deciding factor regarding saturation levels and breakthrough. The main observation being that at hydrophilic angles, water occupies all pores, whereas at hydrophobic angles, water only partially occupies pores, decreasing saturation and breakthrough.

At the angle of $140^{\circ}$, the average saturation level of all three GDLs was $52 \%$, showing that half of the GDL volume could facilitate gaseous flow. These results agree with the work in [14, 28-30], which suggested that the enhancement of hydrophobicity of the GDL will provide space for gaseous transport through the GDL material.

In terms of pressure difference, pressure differences that were applied across the thickness of the sample don't affect saturation levels at breakthrough. At all three pressure differences, all samples showed almost exactly the same saturation levels over the range of contact angles. Pressure difference does however, impact on breakthrough time. 


\section{Conclusions}

This work presents the findings from an investigation into liquid water behaviour in PEMFC GDLs under varying wettability conditions and applied pressure differences. XCT reconstructed models of three types of commercial GDL were input to a two-phase LB model to determine the water's behaviour characteristics.

The work contained in this study observes water transport behaviour in uncompressed GDLs, with no PTFE or MPL applied. The results as such are comparable to ex-situ testing of GDL materials rather than actual invasion patterns in an operational PEMFC.

\subsection{GDL Wettability effects}

The water invasion pattern and the overall saturation level of liquid water in the GDL was heavily influenced by the material wettability (contact angle). Stable displacement was observed in all GDLs with hydrophilic contact angles, whereas capillary fingering was observed in hydrophobic GDLs. Saturation levels decreased in the region of $50 \%$ in highly hydrophobic GDLs, which left $50 \%$ of the pores available for gas transport. The transition between the two phenomena occurred between $90^{\circ}$ and $120^{\circ}$.

\subsection{Applied Pressure effects}

Breakthrough was partially controlled by GDL wettability, with higher pressure differences influencing breakthrough at high contact angles. Generally speaking, liquid water broke through the entire sample thickness at $10 \mathrm{kPa}$ and $15 \mathrm{kPa}$ pressure differences. However, at $5 \mathrm{kPa}$ breakthrough rarely occurred. This suggests that a $5 \mathrm{kPa}$ difference in pressure is insufficient to encourage water breakthrough.

Regarding invasion patterns and saturation levels under these conditions, differing applied pressures showed no influence on either aspect. 
When assessing the water saturation figures above, it is clear that all three applied pressure difference showcase the same trend. The GDL samples become fully saturated at hydrophilic contact angles and partially saturated at hydrophobic angles.

\subsection{GDL Structure effects}

Regarding invasion patterns, all three GDL samples studied showed differences in capillary fingering in the hydrophobic case. In the felt sample, liquid water invaded mainly in the through-plane direction, whereas the paper with a 2D binder showed invasion in the in-plane direction. For the paper GDL with a 3D binder, invasion patterns were observed in both the through and in-plane directions.

Additionally, the structure of each GDL proved to heavily influence the water breakthrough characteristics. This difference in breakthrough nature is due to the number of through-plane fibres in the felt GDL rather than paper. Through-plane fibres favour water transport at hydrophilic contact angles when water interaction is adhesive in nature. The paper GDL with a 3D binder also showed through-plane fibres as with the felt, both leading to water travel in the same direction. However, the 2D bound paper GDL contains mainly in-plane fibres, and thus, liquid water would attach to these fibres, and move along in the in-plane direction.

GDL structure was found to have negligible breakthrough influence with hydrophobic GDL materials. On the other hand, each GDL material contributed to a significant difference in the capillary fingering behaviour when under hydrophobic contact angles.

\section{Acknowledgement}

The authors would like to gratefully acknowledge The Royal Thai Government Scholarship for funding the PhD research study of Fontip Jinuntuya and the UK Department of Trade and Industry 
(DTI) and Engineering and Physical Sciences Research Council (EPSRC) for funding this research work under Grant Number: TP/6/DAM/6/S/K3032H.

\section{References}

[1] Bazylak, A., Liquid water visualization in PEM fuel cells: A review. International Journal of Hydrogen Energy, 2009. 34(9): p. 3845-3857.

[2] Litster, S., D. Sinton, and N. Djilali, Ex situ visualization of liquid water transport in PEM fuel cell gas diffusion layers. Journal of Power Sources, 2006. 154(1): p. 95-105.

[3] Bazylak, A., et al., Effect of compression on liquid water transport and microstructure of PEMFC gas diffusion layers. Journal of Power Sources, 2007. 163(2): p. 784-792.

[4] Pasaogullari, U. and C.Y. Wang, Liquid water transport in gas diffusion layer of polymer electrolyte fuel cells. Journal of the Electrochemical Society, 2004. 151(3): p. A399-A406.

[5] Nam, J.H. and M. Kaviany, Effective diffusivity and water-saturation distribution in single- and two-layer PEMFC diffusion medium. International Journal of Heat and Mass Transfer, 2003. 46(24): p. 4595-4611.

[6] Natarajan, D. and T. Van Nguyen, A Two-Dimensional, Two-Phase, Multicomponent, Transient Model for the Cathode of a Proton Exchange Membrane Fuel Cell Using Conventional Gas Distributors. Journal of The Electrochemical Society, 2001. 148(12): p. A1324-A1335.

[7] Siegel, N.P., et al., A two-dimensional computational model of a PEMFC with liquid water transport. Journal of Power Sources, 2004. 128(2): p. 173-184.

[8] Wang, Z.H., C.Y. Wang, and K.S. Chen, Two-phase flow and transport in the air cathode of proton exchange membrane fuel cells. Journal of Power Sources, 2001. 94(1): p. 40-50. 
[9] You, L.X. and H.T. Liu, A two-phase flow and transport model for the cathode of PEM fuel cells. International Journal of Heat and Mass Transfer, 2002. 45(11): p. 2277-2287.

[10] Wang, Y. and C.Y. Wang, A non-isothermal, two-phase model for polymer electrolyte fuel cells. Journal of the Electrochemical Society, 2006. 153(6): p. A1193-A1200.

[11] Mukherjee, P.P., Q.J. Kang, and C.Y. Wang, Pore-scale modeling of two-phase transport in polymer electrolyte fuel cells-progress and perspective. Energy \& Environmental Science, 2011. 4(2): p. 346-369.

[12] Jiao, K. and X. Li, Water transport in polymer electrolyte membrane fuel cells. Progress in Energy and Combustion Science, 2011. 37(3): p. 221-291.

[13] Wang, Y., et al., A review of polymer electrolyte membrane fuel cells: Technology, applications, and needs on fundamental research. Applied Energy, 2011. 88(4): p. 981-1007.

[14] Chapuis, O., et al., Two-phase flow and evaporation in model fibrous media Application to the gas diffusion layer of PEM fuel cells. Journal of Power Sources, 2008. 178(1): p. 258-268.

[15] Hinebaugh, J., Z. Fishman, and A. Bazylak, Unstructured Pore Network Modeling with Heterogeneous PEMFC GDL Porosity Distributions. Journal of The Electrochemical Society, 2010. 157(11): p. B1651-B1657.

[16] Chraibi, H., et al., Influence of wettability on liquid water transport in gas diffusion layer of proton exchange membrane fuel cells (PEMFC). arXiv preprint arXiv:0909.2947, 2009.

[17] Hinebaugh, J. and A. Bazylak, Condensation in PEM Fuel Cell Gas Diffusion Layers: A Pore Network Modeling Approach. Journal of The Electrochemical Society, 2010. 157(10): p. B1382-B1390. 
[18] Medici, E.F. and J.S. Allen, The Effects of Morphological and Wetting Properties of Porous Transport Layers on Water Movement in PEM Fuel Cells. Journal of the Electrochemical Society, 2010. 157(10): p. B1505-B1514.

[19] Sinha, P.K. and C.Y. Wang, Liquid water transport in a mixed-wet gas diffusion layer of a polymer electrolyte fuel cell. Chemical Engineering Science, 2008. 63(4): p. 1081-1091.

[20] Sinha, P.K. and C.Y. Wang, Pore-network modeling of liquid water transport in gas diffusion layer of a polymer electrolyte fuel cell. Electrochimica Acta, 2007. 52(28): p. 7936-7945.

[21] Hinebaugh, J. and A. Bazylak. PEM Fuel Cell Gas Diffusion Layer Modelling of Pore Structure and Predicted Liquid Water Saturation. in ASME $20119^{\text {th }}$ International Conference on Fuel Cell Science, Engineering and Technology collocated with ASME 2011 5th International Conference on Energy Sustainability. 2011. American Society of Mechanical Engineers.

[22] Lee, K.J., J.H. Nam, and C.J. Kim, Pore-network analysis of two-phase water transport in gas diffusion layers of polymer electrolyte membrane fuel cells. Electrochimica Acta, 2009. 54(4): p. $1166-1176$.

[23] Lee, K.J., J.H. Nam, and C.J. Kim, Steady saturation distribution in hydrophobic gas-diffusion layers of polymer electrolyte membrane fuel cells: A pore-network study. Journal of Power Sources, 2010. 195(1): p. 130-141.

[24] Rama, P., et al., An X-Ray Tomography Based Lattice Boltzmann Simulation Study on Gas Diffusion Layers of Polymer Electrolyte Fuel Cells. Journal of Fuel Cell Science and Technology, 2010. 7(3): p. 031015-031015.

[25] Mukherjee, P.P., et al., Numerical Modeling of Two-Phase Behavior in the PEFC Gas Diffusion Layer. ECS Transactions, 2010. 26(1): p. 97-106. 
[26] Koido, T., T. Furusawa, and K. Moriyama, An approach to modeling two-phase transport in the gas diffusion layer of a proton exchange membrane fuel cell. Journal of Power Sources, 2008. 175(1): p. $127-136$.

[27] Mukherjee, P.P., C.-Y. Wang, and Q. Kang, Mesoscopic modeling of two-phase behavior and flooding phenomena in polymer electrolyte fuel cells. Electrochimica Acta, 2009. 54(27): p. 68616875.

[28] Rama, P., et al., Simulation of liquid water breakthrough in a nanotomography reconstruction of a carbon paper gas-diffusion layer. AIChE Journal, 2012. 58(2): p. 646-655.

[29] Gao, Y., et al., Lattice Boltzmann simulation of water and gas flow in porous gas diffusion layers in fuel cells reconstructed from micro-tomography. Computers \& Mathematics with Applications, 2013. 65(6): p. 891-900.

[30] Rama, P., et al., A Numerical Study of Structural Change and Anisotropic Permeability in Compressed Carbon Cloth Polymer Electrolyte Fuel Cell Gas Diffusion Layers. Fuel Cells, 2011. 11(2): p. $274-285$.

[31] Rama, P., et al., Multiscale Modeling of Single-Phase Multicomponent Transport in the Cathode Gas Diffusion Layer of a Polymer Electrolyte Fuel Cell. Energy \& Fuels, 2010. 24(5): p. 3130-3143.

[32] Shan, X.W. and H.D. Chen, Lattice Boltzmann Model for Simulating Flows with Multiple Phases and Components. Physical Review E, 1993. 47(3): p. 1815- 1819.

[33] Shan, X.W. and H.D. Chen, Simulation of Nonideal Gases and Liquid-Gas Phase-Transitions by the Lattice Boltzmann-Equation. Physical Review E, 1994. 49(4): p. 2941-2948.

[34] Hao, L. and P. Cheng, Lattice Boltzmann simulations of water transport in gas diffusion layer of a polymer electrolyte membrane fuel cell. Journal of Power Sources, 2010. 195(12): p. 3870-3881. 